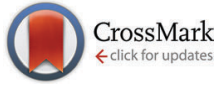

Cite this: Phys. Chem. Chem. Phys., 2015, 17, 18262

Received 21st May 2015,

Accepted 11th June 2015

DOI: $10.1039 / \mathrm{c5cp02950c}$

www.rsc.org/pccp

\section{Study of the reactivity of silica supported tantalum catalysts with oxygen followed by in situ HEROS}

\author{
Wojciech Błachucki, ${ }^{a}$ Jakub Szlachetko, ${ }^{\text {bc }}$ Yves Kayser, $^{\mathrm{b}}$ Jean-Claude Dousse, ${ }^{a}$ \\ Joanna Hoszowska, ${ }^{a}$ Daniel L. A. Fernandes ${ }^{d}$ and Jacinto Sá*de
}

\begin{abstract}
We report on the reactivity of grafted tantalum organometallic catalysts with molecular oxygen. The changes in the local Ta electronic structure were followed by in situ high-energy resolution off-resonant spectroscopy (HEROS). The results revealed agglomeration and formation of $\mathrm{Ta}$ dimers, which cannot be reversed. The process occurs independently of starting grafted complex.
\end{abstract}

Hybrid materials with well-defined organometallic fragments grafted on conventional supports are attractive in many applications, such as catalysis and functional materials. ${ }^{1}$ Numerous studies have focused on the modification of the external coordination sphere of silica grafted complex, and the consequences for catalytic properties of the resulting hybrid material. ${ }^{2}$ One of the most studied surface organometallic species is tantalum hydride supported on silica dehydroxylated at $700{ }^{\circ} \mathrm{C} .{ }^{3}$ This material has shown various catalytic properties (alkane metathesis, hydro-metathesis, non-oxidative coupling of methane) and unprecedented reactivity in nitrogen activation. ${ }^{4}$ The catalyst is prepared in two steps. In first instance $\mathrm{Ta}(=\mathrm{CH} t \mathrm{Bu})\left(\mathrm{CH}_{2} t \mathrm{Bu}\right)_{3}$ complex reacts with the $\mathrm{OH}$ groups of a silica dehydroxylated leading to the formation of monosiloxy surface species $\left[\left(\equiv \mathrm{SiO}_{2}\right) \mathrm{Ta}(=\mathrm{CH} t \mathrm{Bu})\left(\mathrm{CH}_{2} t \mathrm{Bu}\right)_{2}\right]$. The surface species is next exposed to hydrogen to form $\left[\left(\equiv \mathrm{SiO}_{2}\right) \mathrm{TaH}_{3}\right]^{5}$

$\left[\left(\equiv \mathrm{SiO}_{2}\right) \mathrm{TaH}_{3}\right]$ is highly sensitive to the presence of oxygenated molecules like alcohols, water and molecular oxygen, which often leads to an irreversible deactivation of the catalyst. This hinders the wider application of these highly active and selective catalysts. Thus monitoring what happens to the catalyst in the presence of molecular oxygen offers clues on complex reactivity with oxygen and deactivation mechanism that can be used to prevent or revert the process. Experimental determination of the electronic structure of the tantalum under in situ conditions is challenging. To monitor the

\footnotetext{
${ }^{a}$ Department of Physics, University of Fribourg, Fribourg, Switzerland.

E-mail: wojciech.blachucki@unifr.ch

${ }^{b}$ Paul Scherrer Institute, Villigen PSI, Switzerland

${ }^{c}$ Institute of Physics, Jan Kochanowski University, Kielce, Poland

${ }^{d}$ Department of Chemistry, Uppsala University, Sweden

${ }^{e}$ Institute of Physical Chemistry, Polish Academy of Sciences, Warsaw, Poland.

E-mail: jacinto.sa@kemi.uu.se
}

subtle changes of the electronic configuration of the Ta-site requires experimental techniques of high sensitivity. Moreover, because of relatively quick changes of the Ta electronic structure during reaction conditions, acquisitions times down to few seconds are necessary in order to capture all the formed intermediates. In the present study, we applied the high energy resolution off-resonant spectroscopy (HEROS) to follow the electronic structure changes of tantalum catalysts. The HEROS technique, following theoretical investigations of Tulkki and Åberg, ${ }^{6}$ relies on the resonant inelastic X-ray scattering $(\mathrm{RIXS})^{7}$ - a second order atomic process involving excitation of a core level electron to an unoccupied state above the Fermi level and filling the created hole by another inner shell electron. In a HEROS measurement the material under study is irradiated with an X-ray beam of energy detuned below a given core level binding energy and the induced fluorescence is detected by means of a wavelength dispersive-type spectrometer. It has been demonstrated that emission spectra obtained in this way provide element-selective information about the density of unoccupied states. ${ }^{8}$ Thanks to the scanning-free arrangement, the HEROS spectra can be recorded with a sub-second time resolution and with an energy resolution being independent of the initial state lifetime broadening. ${ }^{9}$ Moreover, we showed that the self-absorption process does not affect the shape of HEROS spectra, ${ }^{10}$ making it a powerful technique to quantify the desired changes. Finally, thanks to the penetrating properties of X-rays the experiments may be performed in situ. Thanks to these characteristics of HEROS, the Ta electronic structure could be probed in real-time under reaction conditions.

Herein, we report an in situ time-resolved HEROS study on reactivity of supported tantalum organometallic with molecular oxygen. The supported complex of $\mathrm{Ta}\left(\left[\left(\equiv \mathrm{SiO}_{2}\right) \mathrm{Ta}(=\mathrm{CH} t \mathrm{Bu})\right.\right.$ $\left.\left(\mathrm{CH}_{2} t \mathrm{Bu}\right)_{2}\right]$ or $\left.\left[\left(\equiv \mathrm{SiO}_{2}\right) \mathrm{TaH}_{3}\right]\right)$ was loaded into a quartz capillary reactor cell in a glove box, and exposed to $20 \mathrm{ppm}$ of molecular oxygen at room temperature. The complex was next irradiated with an X-ray beam of energy set at $14 \mathrm{eV}$ below the elemental Ta $\mathrm{L}_{3}$-edge binding energy $(9.881 \mathrm{keV})$ and the fluorescence was recorded in the energy domain around the Ta $L \alpha_{1}$ emission line $(8.146 \mathrm{keV})$. Thus obtained HEROS spectra were collected one by one with an acquisition time of $20 \mathrm{~s}$ each. Note that the Ta $\mathrm{L}_{3}$-edge 

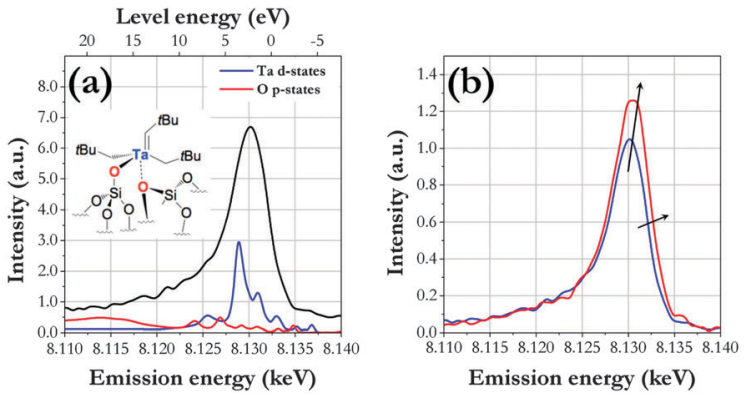

Emission energy (keV)

Fig. 1 (a) HEROS spectrum (black) and calculated density of unoccupied $\mathrm{Ta}$ d- and $\mathrm{O} \mathrm{p}$-states for $\left[\left(\equiv \mathrm{SiO}_{2}\right) \mathrm{Ta}(=\mathrm{CH} t \mathrm{Bu})\left(\mathrm{CH}_{2} t \mathrm{Bu}\right)_{2}\right]$. The level energy scale on the top axis refers only to the presented DOS and shows its distribution around the Fermi level. (b) Comparison between the HEROS spectra of $\left[\left(\equiv \mathrm{SiO}_{2}\right) \mathrm{Ta}(=\mathrm{CH} t \mathrm{Bu})\left(\mathrm{CH}_{2} \mathrm{tBu}\right)_{2}\right]$ (blue) and $\left[\left(\equiv \mathrm{SiO}_{2}\right) \mathrm{TaH}_{3}\right]$ (red).

permits to probe directly the bonding states of tantalum that are involved in catalysis.

Fig. 1(a) shows the HEROS spectrum of $\left[\left(\equiv \mathrm{SiO}_{2}\right) \mathrm{Ta}(=\mathrm{CH} t \mathrm{Bu})-\right.$ $\left.\left(\mathrm{CH}_{2} t \mathrm{Bu}\right)_{2}\right]$ and the orbitals calculated with FEFF $9 .{ }^{11}$ On the basis of FEFF 9 calculations, we conclude that the Ta $5 \mathrm{~d}$ orbitals are the main contributors to the empty states of the complex with a minor contribution of $\mathrm{O} 2 \mathrm{p}$ orbitals. The signal is significantly different from $\left[\left(\equiv \mathrm{SiO}_{2}\right) \mathrm{TaH}_{3}\right]$ (Fig. 1b). The hydride version has a more intense white line, which indicates an increase of Ta empty 5d-orbitals. The well-known d-band model describes how the centre and width of the d-band energy can be used to understand catalytic activity. ${ }^{12}$ According to this model a higher d-band centre and a decreasing width are indicative of stronger bonding to admolecules. Thus, the hydride version favours adsorption of reactants, which is the initial step of any catalytic reaction. The shift to a higher energy of the HEROS spectrum relates to a shift in the Fermi level position. At this point, we would like to emphasize two interesting features of our study. Firstly, the present work represents the first measurement able to depict the electronic structure of the active catalyst. Secondly, the spectral difference between the precursor and the active catalyst was only made visible thanks to the high-spectral resolution of the HEROS technique.

The exposure of $\left[\left(\equiv \mathrm{SiO}_{2}\right) \mathrm{Ta}(=\mathrm{CH} t \mathrm{Bu})\left(\mathrm{CH}_{2} t \mathrm{Bu}\right)_{2}\right]$ and $\left[\left(\equiv \mathrm{SiO}_{2}\right)-\right.$ $\mathrm{TaH}_{3}$ ] to molecular oxygen $(20 \mathrm{ppm})$ dramatically changes the electronic structure of Ta (Fig. 2). A doublet feature instead of a singlet dominates now the HEROS spectra. The doublet is present after oxidation of both materials but the peak ratios are not the same, advocating the presence of a second component. The appearance of a doublet suggests indeed the formation of $\mathrm{Ta}=$ oxo dimeric surface species with octahedral coordination, ${ }^{13}$ which is consistent with the calculations done with FEFF 9 (Fig. 3). The main peak relates to the 5d-orbitals of the Ta absorber and the second peak relates to the 5d-orbitals of the Ta spectator.

We were able to retrieve the HEROS spectra for mono- and di-meric tantalum species (Fig. 4) and their concentrations after oxidation of $\left[\left(\equiv \mathrm{SiO}_{2}\right) \mathrm{Ta}(=\mathrm{CH} t \mathrm{Bu})\left(\mathrm{CH}_{2} t \mathrm{Bu}\right)_{2}\right]$ and $\left[\left(\equiv \mathrm{SiO}_{2}\right) \mathrm{TaH}_{3}\right]$. The spectrum of the dimeric species reveals the characteristic doublet associated to the contribution of the 5d-orbitals of Ta in absorber and spectator positions, whereas the monomeric species is a singlet with a shoulder related to an increased contribution of

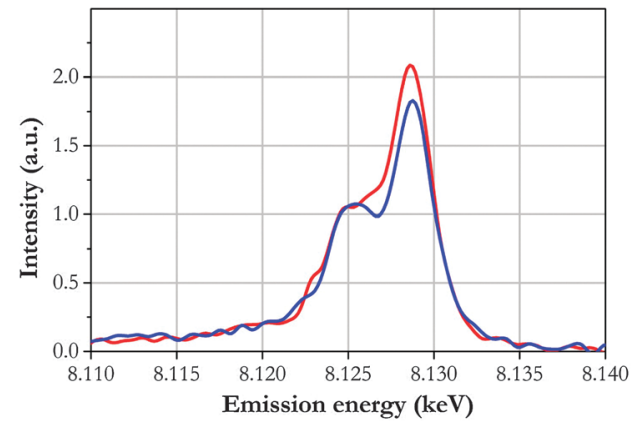

Fig. 2 HEROS spectra of the oxidation of $\left[\left(\equiv \mathrm{SiO}_{2}\right) \mathrm{Ta}(=\mathrm{CH} \mathrm{Hu})\left(\mathrm{CH}_{2}+\mathrm{Bu}\right)_{2}\right]$ (blue) and $\left[\left(\equiv \mathrm{SiO}_{2}\right) \mathrm{TaH}_{3}\right]$ (red).

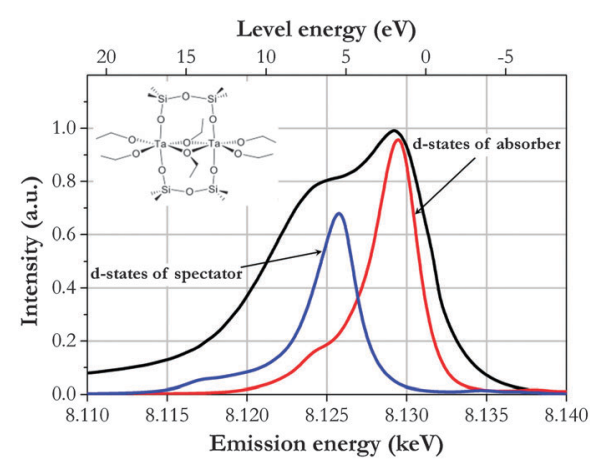

Fig. 3 The off-resonant Ta $L \alpha_{1}$ emission spectrum (black) and the density of unoccupied d-states of absorber (red) and spectator (blue) Ta atoms calculated for $\mathrm{Ta}=$ oxo dimeric surface species with octahedral coordination. The calculations were done with FEFF 9. The level energy scale is to provide information about the presented DOS distribution around the Fermi level.

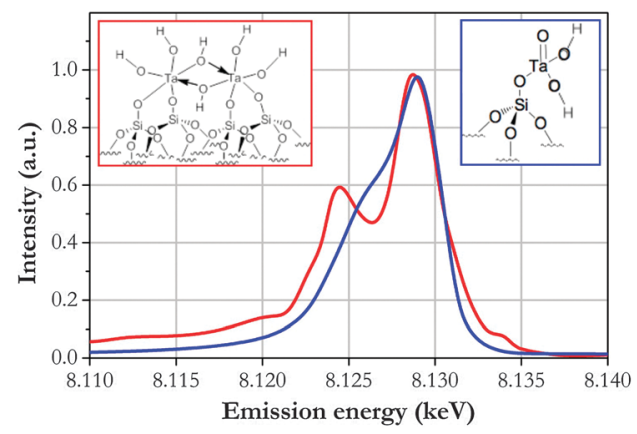

Fig. 4 Normalized HEROS spectra for monomeric (blue) and dimeric (red) species, resulting from oxidation of Ta complexes.

the $\mathrm{O} 2 \mathrm{p}$ orbitals. In the case of $\left[\left(\equiv \mathrm{SiO}_{2}\right) \mathrm{Ta}(=\mathrm{CH} t \mathrm{Bu})\left(\mathrm{CH}_{2} t \mathrm{Bu}\right)_{2}\right]$ after oxidation, $61 \%$ of the species are dimeric, whereas in the case of $\left[\left(\equiv \mathrm{SiO}_{2}\right) \mathrm{TaH}_{3}\right]$ we found that $52 \%$ are present as dimers. We believe that species grafted in isolated $\mathrm{SiOH}$ groups lead to the formation of monomeric species, while complexes grafted on neighbouring $\mathrm{SiOH}$ lead to the formation of dimeric species upon exposure to molecular oxygen. However, some migration process and/ or different reactivity with oxygen also needs to be considered since $\left[\left(\equiv \mathrm{SiO}_{2}\right) \mathrm{TaH}_{3}\right]$ is formed from $\left[\left(\equiv \mathrm{SiO}_{2}\right) \mathrm{Ta}(=\mathrm{CH} t \mathrm{Bu})\left(\mathrm{CH}_{2} t \mathrm{Bu}\right)_{2}\right]$, meaning that the number of isolated and neighbouring $\mathrm{SiOH}$ are the same. 


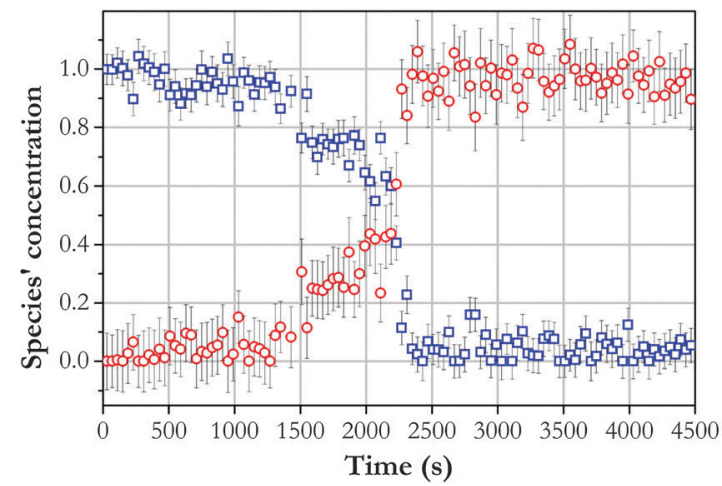

Fig. 5 Spectral evolution as a function of time on stream. The data was fitted with two components $(\square)\left[\left(\equiv \mathrm{SiO}_{2}\right) \mathrm{Ta}(=\mathrm{CHtBu})\left(\mathrm{CH}_{2} t \mathrm{Bu}\right)_{2}\right] ;(\mathrm{O})$ after oxidation.

A major advantage of recording HEROS spectra with a wavelength dispersive von Hamos-type spectrometer is the ability of the latter to acquire the full spectrum in a shot-toshot basis. The time resolution is therefore determined by the flux of the incident photon beam and the specimen concentration. In the present case, to determine changes in the catalysts time on stream, the time-resolved HEROS study was performed with a time resolution of $20 \mathrm{~s}$. In addition to the temporal resolution, a reliable measurement of the ratio of concentrations of the two species as a function of time was required. This could be indeed achieved with the HEROS technique because the measured spectral profiles were not distorted by self-absorption effects in contrast to conventional XAS. The HEROS technique allows therefore for a quantitative determination of sample composition and to study its evolution under reaction conditions.

Fig. 5 shows the signal deconvolution done with initial and final state fingerprint spectra. The spectral changes could be successfully quantified by fitting the spectra with two components. The signal evolution suggests an intermediate step between 1500-2000 s before the quick transformation of all the species to the final states, most likely due to the different reaction rates for oxidation and dimerization.

\section{Conclusions}

It was found that the oxidation of $\left[\left(\equiv \mathrm{SiO}_{2}\right) \mathrm{Ta}(=\mathrm{CH} t \mathrm{Bu})\left(\mathrm{CH}_{2} t \mathrm{Bu}\right)_{2}\right]$ and $\left[\left(\equiv \mathrm{SiO}_{2}\right) \mathrm{TaH}_{3}\right]$ leads to the formation of mono- and di-meric species on $\mathrm{SiO}_{2}$ surface. The appetence to form one or the other species relates to the heterogeneity of the silanol groups on $\mathrm{SiO}_{2}$ surface since isolated $\mathrm{SiOH}$ form monomeric species and neighbouring $\mathrm{SiOH}$ form dimers. The oxidation of these complexes results in the formation of stable and inactive catalysts that precludes simple regeneration processes. Finally, HEROS provided electronic information on Ta complexes, in real-time and with high-energy resolution. This enabled the determination of the electronic structure of active tantalum for the first time. We would like to emphasize that the technique can be adapted to other highly promising grafted catalysts based for example on $\mathrm{W}$ and $\mathrm{Hf}$.

\section{Acknowledgements}

The authors would like to thank Dr Szeto, Dr Mallmann and Dr Taoufik from CNRS-LCOMS, Université Lyon 1, for samples and valuable discussions. The authors also thank the Swiss Light Source at the Paul Scherrer Institute, Switzerland for access to the SuperXAS beam line and laboratories. Three of us (WB, JCD and JH) acknowledge the financial support from the Swiss National Science Foundation.

\section{References}

1 (a) N. Popoff, J. Espinas, J. Pelletier, K. C. Szeto, J. Thivolle-Cazat, L. Delevoye, R. M. Gauvin and M. Taoufik, ChemCatChem, 2013, 5, 1971; (b) N. Karousis, N. Tagmatarchis and D. Tasis, Chem. Rev., 2010, 110, 5366.

2 (a) J. Corker, F. Lefebvre, C. Lecuyer, V. Dufaud, F. Quignard, A. Choplin, J. Evans and J. M. Basset, Science, 1996, 271, 966; (b) N. Popoff, E. Mazoyer, J. Pelletier, R. M. Gauvin and M. Taoufik, Chem. Soc. Rev., 2013, 42, 9035; (c) V. Vidal, A. Theolier, J. Thivolle Cazat and J. M. Basset, Science, 1997, 276, 99.

3 (a) V. Polshettiwar, J. Thivolle-Cazat, M. Taoufik, F. Stoffelbach, S. Norsic and J.-M. Basset, Angew. Chem., Int. Ed., 2011, 50, 2747; (b) M. Taoufik, E. Schwab, M. Schultz, D. Vanoppen, M. Walter, J. Thivolle-Cazat and J. M. Basset, Chem. Commun., 2004, 1434.

4 P. Avenier, M. Taoufik, A. Lesage, X. Solans-Monfort, A. Baudouin, A. de Mallmann, L. Veyre, J. M. Basset, O. Eisenstein, L. Emsley and E. A. Quadrelli, Science, 2007, 317, 1056.

5 V. Vidal, A. Théolier, J. Thivolle-Cazat, J.-M. Basset and J. Corker, J. Am. Chem. Soc., 1996, 118, 4595.

6 J. Tulkki and T. Åberg, J. Phys. B: At. Mol. Phys., 1982, 15, L435. 7 W. Eberhardt, A. P. Hitchcock and N. Kosugi, Eds, J. Electron Spectrosc. Relat. Phenom., 2013, 188, 1, special issue.

8 (a) J. Szlachetko, M. Nachtegaal, J. Sá, J.-Cl. Dousse, J. Hoszowska, E. Kleymenov, M. Janousch, O. V. Safonova, C. Koenig and J. A. van Bokhoven, Chem. Commun., 2012, 48, 10898; (b) J. Szlachetko, D. Ferri, V. Marchionni, A. Kambolis, O. V. Safonova, C. J. Milne, O. Kröcher, M. Nachtegaal and J. Sá, J. Am. Chem. Soc., 2013, 51, 19071.

9 J. Szlachetko, M. Nachtegaal, E. de Boni, M. Willimann, O. Safonova, J. Sá, G. Smolentsev, M. Szlachetko, J. A. van Bokhoven, J.-Cl. Dousse, J. Hoszowska, Y. Kayser, P. Jagodzinski, A. Bergamaschi, B. Schmitt, C. David and A. Luecke, Rev. Sci. Instrum., 2012, 83, 103105.

10 W. Błachucki, J. Szlachetko, J. Hoszowska, J.-Cl. Dousse, Y. Kayser, M. Nachtegaal and J. Sá, Phys. Rev. Lett., 2014, 112, 173003.

11 (a) A. L. Ankudinov, B. Ravel, J. J. Rehr and S. D. Conradson, Phys. Rev. B: Condens. Matter Mater. Phys., 1998, 58, 7565; (b) A. L. Ankudinov, J. J. Rehr, J. Low and S. R. Bare, Phys. Rev. Lett., 2001, 86, 1642.

12 (a) B. Hammer and J. K. Nørskov, Nature, 1995, 376, 238; (b) B. Hammer and J. K. Nørskov, Adv. Catal., 2000, 45, 71. 13 R. N. Kapoor, F. Cervantes-Lee, C. F. Campana, C. Haltiwanger, K. Abney and K. H. Pannell, Inorg. Chem., 2006, 45, 2203. 